Paediatr Paedolog 2015 · 50:131 DOI 10.1007/s00608-015-0295-y Online publiziert: 29. August 2015 (c) Springer-Verlag Wien 2015

\title{
Ingomar Mutz
}

St. Marein i.M., Österreich und ehemaliger Herausgeber von „pädiatrie \& pädologie“

\section{Für eine erfolgreiche Zukunft!}

\section{pädiatrie \& pädologie \\ 블 Springer Medizin}

Die Gründung einer österreichischen Zeitschrift für Pädiatrie mit dem einmaligen Zusatz Pädologie ${ }^{1}$ vor 50 Jahren entsprach dem universellen Geist von Prof. Asperger und der ab dieser Zeit rasanten Entwicklung der Pädiatrie weltweit und auch in Österreich.

In meiner auch 50-jährigen Tätigkeit als Arzt habe ich die leichtere Verfügbarkeit für Publikationen in einer österreichischen Zeitschrift gern angenommen und ab 1975 an insgesamt 28 Beiträgen mitgewirkt.

Nach der Entscheidung der ÖGKJ, die in Deutschland erscheinende und weiter verbreitete Monatsschrift für Kinderheilkunde als offizielles Organ zu nützen, war es deshalb auch eine Ehre für mich, ab 1998 als Herausgeber fungieren zu dürfen. Dabei hat die engagierte und unermüdliche Arbeit von Dr. Renate Höhl die Konzeption sinnvoll als Fortbildungszeitschrift angepasst und meine Tätigkeit extrem erleichtert. Ihr und auch den Mitgliedern des wissenschaftlichen Beirats möchte ich auf diesem Weg herzlich danken.

1 Lehre von der Entwicklung und dem Wachstum des Kindes.
Ebenso dankbar bin ich auch Prof. Dr. Reinhold Kerbl, dass er nach meiner Pensionierung (mit Ende 2006) die Herausgeberschaft übernommen, in seiner präzisen Art weiter verbessert und sich auch wirksam für die Stärkung der Stellung der Kinder- und Jugendheilkunde in Österreich eingesetzt hat.

Meine besten Wünsche begleiten die Pädiatrie und Pädologie für eine erfolgreiche Zukunft.

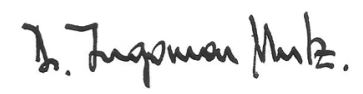

Univ.-Prof. Dr. Ingomar Mutz

\section{Korrespondenzadresse}

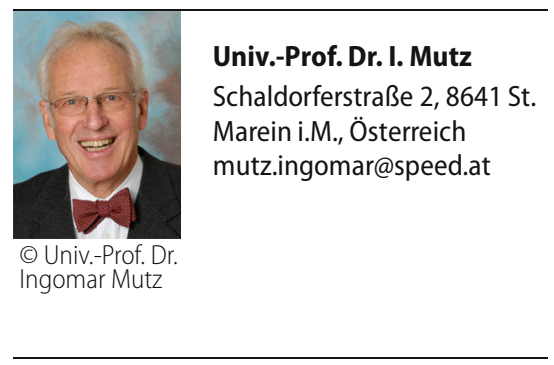

Interessenkonflikt. I. Mutz gibt an, dass kein Interessenkonflikt besteht. 